\title{
Response to the Letter to the Editor Regarding "Micronutrients, Essential Fatty Acids and Bone Health in Phenylketonuria"
}

\author{
Serwet Demirdas ${ }^{a}$ Francjan J. van Spronsen ${ }^{b}$ Carla E.M. Hollak ${ }^{c}$ J. Hanneke van der Lee ${ }^{d}$ \\ Peter H. Bisschop ${ }^{c}$ Fred M. Vaz ${ }^{e}$ Nienke M. ter Horst ${ }^{f}$ M. Estela Rubio-Gozalbo ${ }^{g}$
}

Annet M. Bosch ${ }^{\text {h }}$

${ }^{a}$ Department of Genetics, Erasmus Medical Center, Erasmus University, Rotterdam, The Netherlands; ${ }^{b}$ Division of Metabolic Diseases, Beatrix Children's Hospital, University Medical Center, University of Groningen, Groningen, The Netherlands; ${ }^{\circ}$ Department of Internal Medicine, Division of Endocrinology and Metabolism, Academic

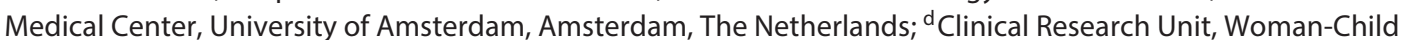

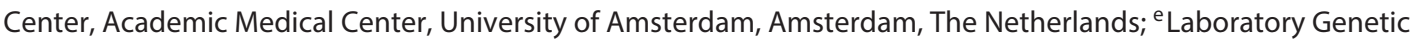
Metabolic Disease, Academic Medical Center, University of Amsterdam, Amsterdam, The Netherlands; ${ }^{\mathrm{f}}$ Department of Dietetics, Academic Medical Center, University of Amsterdam, Amsterdam, The Netherlands; ${ }^{9}$ Department of Pediatrics and Laboratory Genetic Metabolic Diseases, Maastricht University Medical Center, Maastricht, The

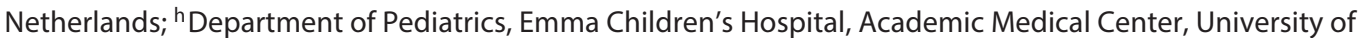
Amsterdam, Amsterdam, The Netherlands

\section{Dear Editors,}

We would like to respond to the letter of our colleagues Hansen, Binkley and Ney about our research published in your journal [1]: a study about micronutrient status, bone mass and fracture rate in a population of patients with phenylketonuria (PKU; $n=60$ ). They present several concerns about our conclusions and we would like to address their remarks.

First of all, Hansen et al. [2] state that our conclusions concerning fracture prevalence are inappropriate. We understand their concern because unfortunately our publication refers to the wrong reference. It should have referred to the publication of Donaldson et al. [3]. This study assesses "the incidence of fractures at any site, among people of all ages, in a sample designed to be representative of the general population, not just those who have sought medical care" ( $n=45,293$ individuals). The authors conclude that for all age groups the age-standardized fracture prevalence was $38.2 \%$ [3]. Therefore, it should not be of concern that our population is mainly pediatric. Furthermore, the population described by the authors is in fact ideal to compare our data to, as we have also (retrospectively) assessed all fractures in our patients, irrespective of location and age using a face-to-face questionnaire.

Hansen et al. [2] state that the fracture prevalence in our population is twice as high as that reported in other studies, referring to Choukair et al. [4] report that 24/56 patients $(43 \%)$ have had a fracture at least once in their lifetime. Importantly, this is comparable to the percentage reported by us [1], even though they describe a population with mainly adult patients.

Hansen et al. [5] also refer to their published meta-analysis concerning bone min- eral density (BMD) and fractures. In this study, they found a much lower fracture rate among patients with PKU [5]. This is intriguing because it could mean that fracture prevalence in patients with PKU might even be below that of the general population. We were not able to reproduce these numbers in our study [6].

Overall, we believe that in the literature, the fracture prevalence in patients with PKU has been overestimated. We would like to refer you to our meta-analysis [6] in which we further elaborate on the limitations in comparing studies concerning bone-density and fractures in patients with PKU.

Second, Hansen et al. [5] wrote that BMD should not be compared using Zscores. We disagree with this statement. The optimal way to evaluate BMD would be to asses Z-scores in children and T-
KARGER

(C) 2018 S. Karger AG, Basel
Serwet Demirdas, MD, $\mathrm{PhD}$ Department of Genetics Erasmus Medical Center, Erasmus University Wytemaweg 80, NL-3015 CN Rotterdam (The Netherlands) E-Mail s.demirdas@erasmusmc.nl 
scores in adults as recommended by the ISCD [7]. In this manner, you can most adequately compare outcomes of individuals with their peers (same age and gender) and use these outcomes to asses which patients are deviant from the norm. The use of $\mathrm{BMD}$ in $\mathrm{g} / \mathrm{cm}^{2}$ would not be adequate in our population - first because of the patient characteristics (relatively small number and heterogeneity in age and gender) and second because we needed to know which patients had a Z-score below -2 to assess if any of them had osteopenia/osteoporosis based on the recommendations of the ISCD [7].

The mean BMD Z-score in our cohort was below -2 in $4.9-7.4 \%$ of the patients, depending on the measured site (respec-

\section{References}

1 Demirdas S, van Spronsen FJ, Hollak CEM, van der Lee JH, Bisschop PH, Vaz FM, Ter Horst NM, Rubio-Gozalbo ME, Bosch AM: Micronutrients, essential fatty acids and bone health in phenylketonuria. Ann Nutr Metab 2017;70:111-121.

2 Hansen KE, Binkley N, Ney DM. High fracture rates in young patients with phenylketonuria. Ann Nutr Metab 2018;72:1-2

3 Donaldson LJ, Reckless IP, Scholes S, Mindell JS, Shelton NJ: The epidemiology of fractures in England. J Epidemiol Community Health $2008 ; 62: 174-180$ tively the lumbar spine and femoral neck [stated as femur in our publication]). These results suggest that mean $\mathrm{BMD}$ is lower in PKU patients compared to the general population but within the normal range in most patients; thus, the clinical relevance of this finding is questionable. Approximately $4.9-7.4 \%$ of early treated patients with PKU may have a BMD Z-score below -2 $\mathrm{SD}$, as opposed to $2.5 \%$ in the general population. This means that approximately 95\% of early treated Dutch patients with PKU are not at risk for low BMD, and this is a much better outcome than expected from reports in the literature $[1,6]$.

Third, and finally, Hansen et al. [2] ask for the number of our patients with Zscores below -2 based on the measured site.
For these results, we refer them to Figure 1 in our publication [1].

We would like to thank our colleagues for giving us the opportunity to further clarify our results. We do agree with them that fracture prevalence/risk in patients with PKU, especially postmenopausal women, should be further investigated because low BMD is slightly more prevalent in our relatively young population than in their healthy peers. However, with our study, we found that fracture incidence in the PKU population (those early diagnosed and continuously treated) is not elevated when compared to the general population and we think the concerns of Hansen et al. [5] are answered by this letter adequately.
4 Choukair D, Kneppo C, Feneberg R, Schonau E, Lindner M, Kolker S, Hoffmann GF, Tonshoff B: Analysis of the functional musclebone unit of the forearm in patients with phenylketonuria by peripheral quantitative computed tomography. J Inherit Metab Dis 2017; 40:219-226.

5 Hansen KE, Ney D: A systematic review of bone mineral density and fractures in phenylketonuria. J Inherit Metab Dis 2014;37:875880 .
6 Demirdas S, Coakley KE, Bisschop HE, Hollak CE, Bosch AM, Singh RH: Bone health in phenylketonuria: a systematic review and meta-analysis. Orphanet Journal of Rare Disease 2015;10:17.

7 Lewiecki EM, Gordon CM, Baim S, Binkley N, Bilezikian JP, Kendler DL, Hans DB, Silverman S, Bishop NJ, Leonard MB, Bianchi ML, Kalkwarf HJ, Langman CB, Plotkin H, Rauch F, Zemel BS: Special report on the 2007 adult and pediatric position development conferences of the International Society for Clinical Densitometry. Osteoporosis Int 2008; 19: 1369-1378. 